\title{
Periferia, literatura y estudios comparados
}

Oscar Vallejos

Universidad Nacional del Litoral

Mimesis de Erich Auerbach (1942) se considera como punto de inflexión para los estudios literarios y comparados. Esta inflexión proviene de una condensación de dos condiciones: las condiciones del trabajo académico y de la producción intelectual. Estas instalan una sensibilidad creciente desde mediados del siglo XX en la vida universitaria y sus mundos circundantes hacia la reflexividad, hacia lo que va a llamarse políticas del conocimiento. Mimesis fue elaborado e incluso imaginado en lo que era la periferia de Europa en el contexto de la segunda Gran Guerra y la situación del pueblo judío. La periferia ingresa al núcleo de los estudios literarios en tanto Auerbach reconoce que Mimesis no hubiera sido posible sin las condiciones peculiares que la vida académica en Estambul planteaba. La otra cuestión es el tema de Mimesis: la representación de la realidad en la literatura. Esta formulación cuidadosa tiene varias posibilidades: la formulación más directa es el problema del realismo; como reconoce Auerbach: una historia sistemática y completa del realismo no ha dejado de aparecer como necesaria. Y lo es porque lo que está en debate es la relación de la literatura con el mundo y con los lectores (y los críticos). Es decir, la cuestión de la representación de la realidad en la literatura no ha dejado de crecer tampoco. Aquí nos centraremos en el tema de la periferia.

\section{Producir en la periferia, producir la periferia}

El término periferia está cargado de significación. Apareció como un término político y cada vez más se desplazó hacia un término descriptivo de las condiciones epistémicas y económicas en las que se organiza mundialmente el sistema de producción y de circulación de conocimiento y mercancías (Cf. Matharan, 2016). La clave que nos interesa es cómo Mimesis replantea el modo en que se produce conocimiento en la periferia y en el contexto de una ciencia y una práctica académica mundializada. Las condiciones que están expresadas por Mimesis son las del exilio y la falta. 
La cuestión del exilio tiene una especificidad que excede la cuestión periférica. El caso de Auerbach y de los profesores e intelectuales judíos europeos ofrecen o transitan la experiencia del exilio como destierro. Muchos intelectuales y profesores nacidos en la periferia fueron al exilio hacia los países centrales también por persecuciones políticas y, de manera específica, forzados por la búsqueda de condiciones para sostener la actividad académica; lo que suele leerse como fuga de cerebros.

Lo que nos interesa aquí es leer el exilio como un principio epistemológico y metodológico para la literatura y los estudios comparados.

El texto de Said (Said, 1984) Reflexiones sobre el exilio plantea que el exilio genera una conciencia contrapuntística y este es justamente uno de los principios metodológicos que conceptualiza y moviliza en su trabajo crítico. Said (1984) incluye un pasaje de Hugo de San Víctor que es el mismo que refiere Auerbach en Filología de la Weltliteratur (Auerbach, 1952): «el hombre perfecto es aquel para quien el mundo entero es una tierra extraña» (Hugo de San Víctor citado por Said, 1984: 193)

Las condiciones por las que Auerbach y Said plantean el exilio son muy distintas; pero estas reflexiones muestran que la condición de extrañamiento es constitutiva de la producción de conocimiento en la periferia. Esta producción siempre es contrapuntística pues, como plantea Vessuri (1984), la periferia mantiene una relación de dependencia respecto de los países centrales en tres aspectos: el de los conceptos, el de los temas de investigación y el de las instituciones que albergan las actividades académicas. A esos tres habría que agregarle un cuarto: el de la lengua.

La producción de conocimiento en la periferia forma parte de un sistema mundial de producción de conocimientos que, como plantea el texto seminal de Basalla (1967), ofrece saberes sobre territorios y pueblos; pero ingresan a ese sistema mundial en tanto son leídos con conceptos o en organizaciones temáticas o en contextos institucionales dependientes de los países centrales y por ello mismo adquieren una condición contrapuntística.

Auerbach insiste en una falta fundamental de la periferia: las bibliotecas (Cf. Auerbach, 1943). Este es un elemento relevante para comprender las condiciones de producción de conocimiento en la periferia. Las bibliotecas son una tecnología para la producción de conocimiento que reorganizaron los europeos; sobre todo a partir del siglo XIX, y como sostiene Mollier (1999), las bibliotecas se constituyen en un espacio para un público que no sólo las frecuenta sino que hace ellas un locus de estudio o de trabajo.

En el Prefacio a la edición estadounidense del texto Introduction aux étude de philologie romane (editado en francés en Estambul en 1943 ya que el francés era la lengua en la que Auerbach dictaba sus clases) Auerbach hace referencia a que estaba lejos de las bibliotecas europeas y norteamericanas (Cf. Auerbach, 1943). Auerbach fue incluso bibliotecario antes de asumir como profesor de Filología en Marburgo, de manera que conocía la tecnología de las bibliotecas europeas con mucho detalle. Si bien continúa el debate acerca de si Estambul contaba o no con una biblioteca que pudiera ser la base material de la investigación de Auerbach (Cf. Seyhan, 2005) lo que hay que comprender es que una biblioteca no es sólo un repositorio de libros y textos sino una tecnología e, incluso, un espacio de socialización. Auerbach pone en visibilidad una condición de la producción de conocimiento en la periferia: el carácter fragmentado del sistema de producción. 
La centralidad de las bibliotecas se discutió en la Universidad Nacional del Litoral en la misma época en la que Auerbach marcha al exilio hacia Estambul. La creación de Institutos de Investigación a fines de la década del treinta del siglo pasado permitió esa discusión. En la medida en que estos Institutos se creaban para recibir a profesores europeos exiliados, la Universidad Nacional del Litoral también se convierte en un refugio de notables como Beppo Levy, Luis Santaló y Aldo Mieli. Aquí cobra especial relieve la biblioteca de historia de la ciencia de Aldo Mieli.

Mieli se traslada desde Francia con su biblioteca. La Universidad Nacional del Litoral lo contrata para dirigir el recién creado Instituto de Historia y Filosofía de la Ciencia (1939). Mieli cede a la Universidad su biblioteca que es considerada como «única en su género» (Cf. Plá, 1972). Allí inicia un proceso de catalogación y de armado de fichas bibliográficas. Sin embargo, el auge de posiciones también fascistas en la Argentina propició la intervención de la Universidad del Litoral por Jordán Bruno Genta. El interventor termina el contrato con Mieli y lo condena a una suerte de exilio dentro del país. Lo relevante es que se produce una disputa entre Mieli y la Universidad del Litoral por la biblioteca; finalmente la Universidad se la restituye. El despido de Mieli no sólo priva a la Universidad del Litoral de un cuadro formado en historia de la ciencia y estudios de sexualidad sino también de su biblioteca. Muchos ańos después de muerto Mieli, su biblioteca ingresa a la Facultad de Exactas de la Universidad de Buenos Aires.

Esta historia muestra que la tecnología de la biblioteca, de absoluta necesidad para las ciencias filológicas e históricas, es efectivamente una falta en la periferia. Y esa falta no sólo es para la filología y la historia clásicas sino también para aquellas que dependen del acceso a los libros del presente, incluso producidos en los territorios periféricos.

De manera que las condiciones de producción de conocimiento en la periferia expresadas por Auerbach marcan una agenda no sólo de estudio sino de políticas del conocimiento. Políticas del conocimiento que no sólo tienen que ver con cómo emergen disciplinas y tradiciones de estudio sino con las condiciones de dependencia académica y con las condiciones materiales que son necesarias para ingresar al sistema mundial de producción de conocimiento.

\section{Referencias bibliográficas}

Auerbach, E. (1942). Mimesis. La representación de la realidad en la literatura occidental. [Traducción de I. Villanueva y E. Imáz]. México: Fondo de Cultura Económica. 1950.

— (1943). Introdução aos estudos literários. [Traducción de José Paulo Paes]. São Paulo: Cosac Naify.

(1953). Filología de la Weltliteratur. [Traducción de Pablo Gianera]. Cuadernos de Teoría y Crítica. (3), 101-114. Viña del Mar. Septiembre de 2017.

Basalla, G. (1967). The spread of the Western Science. Science. 156. 
$611-622$.

Mollier, J.Y. (1999). «Bibliotecas de Babel: colecciones, diccionarios y enciclopedias» en La lectura y sus públicos en la edad contemporánea. Ensayos de historia cultural en Francia. [Traducción de Víctor Goldstein]. Buenos Aires: Ampersand, pp. 161-174. 2013.

Plá, C. (1972). El Instituto de historia y filosofía de la ciencia de la Universidad Nacional del Litoral. Saber y Tiempo. 4 (16), 91-102. Buenos Aires: Universidad Nacional General San Martín. Julio-Diciembre 2003. SAID, E. (1984). «Reflexiones sobre el exilio» en Reflexiones sobre el exilio. Ensayos literarios y culturales. [Traducción de Ricardo García Pérez]. Barcelona: Debate, pp. 179-194. 2005

(1993). Culture e Imperialism. New York: Vintage Books.

Seyhan, A. (2005). «German Academic Exiles in Istanbul: Translation as the Bildung of the Other» en Bermann, S. y Wood, M. (ed.) Nation, Language, and the Ethics of Translation. Princeton: Princeton University Press, pp. 274-288

Vessuri, H. (1984). ¿Qué investigar en América Latina? En «O inventamos o erramos" La ciencia como ideas-fuerza en América Latina. Bernal: Universidad Nacional de Quilmes, pp. 177-190. 